\title{
REVIEW
}

\section{CONCEPT CARING IN NURSING}

\section{Lenka Drahošová, Darja Jarošová}

Department of Nursing and Midwifery, Faculty of Medicine, University of Ostrava, Czech Republic

Received November 10, 2015; Accepted February 1, 2016. Copyright: This is an open access article distributed under the terms of the Creative Commons Attribution International License (CC BY). http://creativecommons.org/licenses/by/4.0/

\begin{abstract}
Aim: The aim of this literature review was to search for qualitative studies focusing on the concept of caring in nursing, to analyse them and to synthesize knowledge that concerns the definition of the concept of caring in nursing from the point of view of nurses and patients. Design: Review. Methods: Qualitative studies were searched for systematically in the electronic databases Academic Search Complete (EBSCO), CINAHL, Medline, Science Direct, and the Wiley Library Online, according to set criteria and defined key words for the period 1970-2015. Seven selected articles were analysed after selection of documents with the aid of a sorting chart. Results: Nurses understand caring in nursing as a relationship with patients which is characterised on the nurses' part by an individual and empathetic approach, attentiveness, experience and sensitivity. Through caring, active communication takes place, providing information which reduces anxiety and leads to the breaking down of barriers. This relationship helps protect patients' autonomy, dignity and comfort. It requires experience on the part of nurses, and it is influenced by the environment. The nurses' personal qualities (what professional knowledge, attitudes and skills they have) and their availability, reliability, and emotional and physical support are important to patients. Conclusion: The concept of caring is a content specific interpersonal process which is characterized by the professional knowledge, skills, personal maturity, and interpersonal sensitivity of nurses, which result in the protection, emotional support, and the meeting of biopsycho-social needs of patients. The results of the overview study could contribute to an explanation and understanding of the nature of caring as a fundamental feature of the discipline of nursing.
\end{abstract}

Keywords: concept caring in nursing, nature of nursing, personality of the nurse, relationship nurse - patient, literature review.

\section{Introduction}

Historically, the description of what caring in nursing actually involves has been defined from different perspectives, from the very meaning and essence of nursing to the phrase, oft-repeated by nurses, that it is everyday direct care of patients. The factual basis for the conceptualisation of caring in the field was laid down by the important academic works of theorists such as Lininger, Watson, Ray, Gait and others that started to appear in the 1970s and 1980s (Smith et al., 2013). The concept of caring in nursing is presented in foreign literature with various definitions. Caring is understood in the Czech sociocultural context as effort or care for the benefit or salutary development of someone or something. We explain caring as to care for, to look after - the verbal noun of the verb "care" (Filipec, 2005). It is a way of connecting with others whereby we become acquainted with the perceptions and experience of the world of the other.

Corresponding author: Lenka Drahošová, Department of Nursing and Midwifery, Faculty of Medicine, University of Ostrava, Syllabova 19, Ostrava, Czech Republic; e-mail: lenka.drahos@gmail.com
It is help for those who need it. It can be in the form of assistance, support and alleviation, or help with improving quality of life or when illness, disability or threats to life are encountered. It is provided in a humane, empathetic and dignified way and serves to meet the needs of individuals and their families. Caring is natural and characteristic of all mankind. It is the noun used to name phenomena which are associated with assistance, support and the easing of life (Kutnohorská, 2007).

If we are to regard caring as, by definition, the very essence of nursing, it is important that we further clarify and emphasize various views or explantions of the word care/caring and the boundaries set for its conceptualisation. Thus, research at this level is essential (Leininger, 1985; Kyle, 1995; Watson, 2002; Smith et al., 2013).
Aim
The aim was to search and analyze qualitative studies focusing on caring in nursing and to gain knowledge regarding definitions, descriptions or clarifications of the content of the concept of care/caring in nursing, 
both from the point of view of patients, and from nurses in different sociocultural environments.

\section{Methods}

\section{Eligibility criteria}

For the analysis, qualitative studies concerned with the concept of caring in nursing were searched. The following selection criteria were specified for the literary review: English language, full text of the article, reviewed articles or expert studies. The first publications dealing with the clarification of the concept of caring in nursing date from the 1970s and 1980s (Smith et al., 2013). For this reason, the time period for the articles searched was determined as from 1970 to 2015. Publications from the early period focused mainly on philosophical treatises. Articles publishing results of qualitative research started to appear later.

\section{Sources}

We used the electronic bibliographic databases Academic Search Complete (EBSCO), CINAHL, Medline, ScienceDirect, and Wiley Library Online to obtain relevant sources.

\section{Search}

The search for relevant articles was from August to September 2015.

As a search strategy, we defined the tags caring, and nursing. We used the Boolean operators "OR" and
"AND" and further limited key words with quotation marks, "caring in nursing", to ensure a search for this specific word combination. Articles which did not contain the key words, articles published in languages other than English or books or book reviews were eliminated from initial reviews. We provided content analysis of publications which contained the stated key words. Articles which did not fulfil the stated criteria were eliminated, as were abstracts, articles of non-reviewed magazines and documents (systematic overviews, book reviews, articles) which did not deal with clarification of the concept. We used gradual elimination of studies according to PRISMA (Figure 1) recommendations. After 143 searches, 51 articles fulfilled the criteria. Articles which described quantitative studies were gradually eliminated.

\section{Study selection and data analyses}

After a further authentication of the articles, only qualitative studies were chosen for final analysis. Relevant studies were read critically, analyzed, and described in detail. The methodological quality of studies was not evaluated. Survey data were processed in the form of comparative tables. The tables helped to identify key characteristics of the concept of caring in nursing that emerged in connection with the set of studies analyzed. These characteristics were then synthesized into larger complexes.

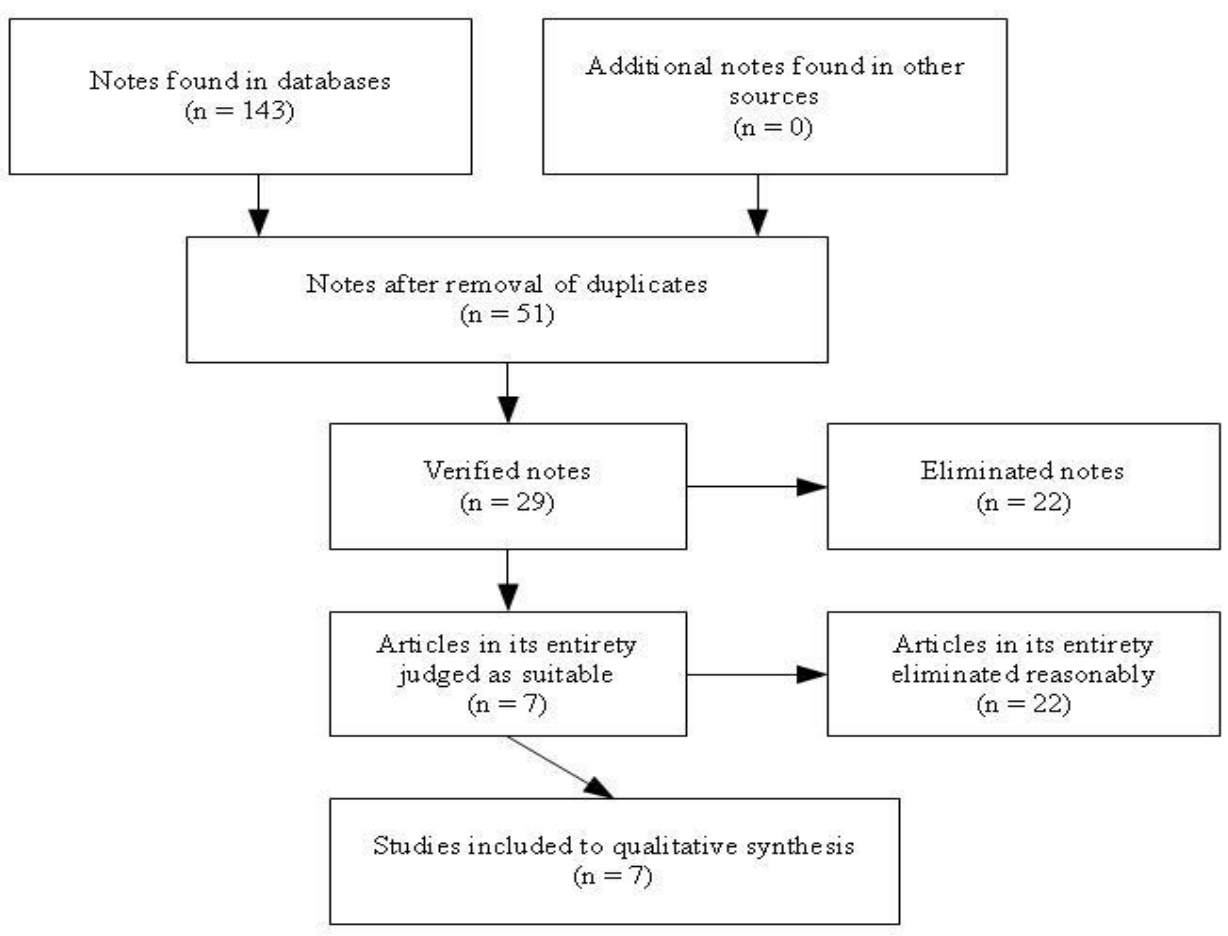

Figure 1 Process of the choice and classification of studies 


\section{Results}

The results of the analysis of identified articles shows that the explanation of the term caring in nursing can be described from different perspectives. (Table 1) Two central aspects are important in expressing the concept of caring in nursing: the view of nurses and the view of patients. Nurses understand caring mainly as the protection and support of the best interests of the patient, as their own nursing intervention or as a context linking more aspects. Some see a philosophical aspect to caring, describing it as way of life, and way of understanding the nature of nursing. Patients described caring primarily as emotional and physical support, in which the individual personality of the nurse is a very important consideration.

\section{Caring in nursing from the point of view of nurses}

Altogether five articles by Andersson et al. (2015), Wilkin and Slevin (2004), Yam and Rossiter (2009), Gustafsson et al. (2009), and Cheung (1998) were used for synthesis of the following information. Several aspects were identified according to which it is possible to describe caring in nursing: caring as the relationship between nurse and patient, caring as protection and support of the best interests of the patient, caring as a nursing intervention, caring as a contextual link to multiple aspects, caring as a way of life, and caring as a way to understand the very essence of nursing.

\section{Caring as relationship between nurse and patient}

Caring perceived this way emphasizes the creation of a quality relationship between nurses and patients (Wilkin, Slevin, 2004; Gustafsson et al., 2009; Yam, Rossiter, 2009; Andersson et al., 2015). Nurses perceive themselves as an "ethical instrument of care", and try to come to an individual understanding of every patient and the impact of the illness on their everyday life. They express a sincere desire to listen and help, through attentiveness and charity, and this attentiveness is the essence of caring. They state, however, that the courage and strength of their own personalities are necessary for the success of this approach. Experience and sensitivity are important aspects of caring, and they emphasize the therapeutic effect of touch, not only as a means of greeting but also as a show of respect for the person as a whole (Wilkin, Slevin, 2004; Yam, Rossiter, 2009; Andersson et al., 2015). Nurses in intensive care put an emphasize on the provision of information, which reduces patient anxiety, and activities to overcome difficulties, for example, when the patient is unconscious, unresponsive, or intubated (Wilkin, Slevin, 2004). Asian nurses also attach great importance to effective communication, which is associated with active listening, understanding and showing sensitivity towards the patient (Yam, Rossiter, 2009). Such an approach helps to create a mutually beneficial relationship, making information transfer and explanations easier. At the same time, it increases patients' awareness of their condition and competence to make their own decisions regarding their health. Nurses also mention the importance of well-kept nursing documentation, which proves to be an important source of information in relation to the patient.According to nurses, the interaction between nurses and patients is a crucial and integral part of holistically conceived care (Wilkin, Levin, 2004).

Caring as protection and support of the best interest of the patient

From this perspective, caring is perceived as the careful treatment of the patient in cooperation with other medical professionals. Nurses are holders of expert information on the current status of the patients and their wishes. Nurses also act as advocates and guardians of patients' rights, they consider care from the point of view of the patient and also regard the situation in a broader context. Nurses support their patients when unconscious or under sedatives, and when a multidisciplinary team is treating them (Wilkin, Slevin, 2004; Gustafsson et al., 2009; Andersson et al., 2015). At the same time, nurses consider themselves as guardians of patients, protecting them from suffering, respecting their psychological and physical dispositions, and the extent to which they want to participate in their own care. In addition, nurses understand this protection as preserving and bolstering the dignity of patients, and the perception of themselves as human beings. Nurses ensure patients' comfort, being ever present with patients, and always available for them. Not only is it important to nurses that patients are clean and without pain but also that patients feel comfortable and relaxed, which can be achieved through quality communication, mental health care and the preservation of their privacy (Cheung, 1998; Wilkin, Slevin, 2004; Andersson et al., 2015). Wilkin and Slevin go on to refer to caring as support of patients and their relatives, providing hope, support and spiritual care. They emphasize the importance of empathy, for example, to emphasize with the feelings which a critically ill patient is experiencing and to try to find out their current needs. Experience of understanding human suffering in illness is connected with personal development and growth. It is beneficial for the patient and it increases the personal and professional potential of the nurse. 
Table 1 Overview of studies related to the concept of caring in nursing

\begin{tabular}{|c|c|c|c|c|}
\hline $\begin{array}{l}\text { Author } \\
\text { /date }\end{array}$ & Hypotheses/aims & $\begin{array}{l}\text { Kind of research } \\
\text { approach/method }\end{array}$ & $\begin{array}{l}\text { Type of respondents } \\
\text { /number }\end{array}$ & Finding \\
\hline $\begin{array}{l}\text { Andersson } \\
\text { et al. } \\
\text { (2015) }\end{array}$ & $\begin{array}{l}\text { To understand and to } \\
\text { describe the nature of the } \\
\text { concept of caring in } \\
\text { registered nurses. }\end{array}$ & $\begin{array}{l}\text { Phenomenological approach, } \\
\text { interview with the initial pilot } \\
\text { tested semi-open question: "Could } \\
\text { you tell me what caring means to } \\
\text { you and your clinical work as a } \\
\text { nurse?" With prompts e.g., "How?" }\end{array}$ & $\begin{array}{l}21 \text { nurses (female } 20: 1 \\
\text { male), average age } 44.1 \\
\text { years. } \\
\text { Coronary care unit in } \\
\text { Sweden. }\end{array}$ & $\begin{array}{l}\text { Four descriptive categories: } \\
\text { 1. Caring focused on the person, } \\
\text { 2. Caring as protection of the interest } \\
\text { of the patient } \\
\text { 3. Caring as intervention of the nurse } \\
\text { 4. Caring- contextual links with } \\
\text { multiple meanings }\end{array}$ \\
\hline
\end{tabular}

Gustafsson To describe and to clarify Phenomenological- hermeneutic Five registered nurses Caring in nursing as defence of et al. the experience and approach inspired by Paul Ricoeur, with 6-35 years' clients, overall responsibility for care (2009) importance of caring in developed by Lindseth and experience, who (provided by a team), importance of nursing for registered Norberg working with life provide care to bigger the care, perceived as paradoxes nurses working night experience, interview with open groups of elderly nurses are near but far, independent shifts with large groups questions which focusing on the patients living in yet dependent on the team, they must of elderly patients. experience of caring in nursing: different institutions in respond to professional and personal "What does caring mean in your Sweden. demands (we are registered nurse), particular community work and work at night? What experience do you have of caring?" must be a guarantee of ethical, quality and competent care for elderly patients.

Cheung To explain and to Phenomenological approach. 27 persons (four male), Caring can be considered as the (1998) interpret caring in Unstructured interview containing ten nurses from ontological and epistemological nursing. the question: "What is your practice, nine students basis of nursing. Caring as a way of definition of caring in nursing?" (studying for 18 life and way of finding the meaning months), eight teachers and purpose of nursing. Caring as a of nursing in Australia. way of understanding the nature of nursing, thinking and conduct of nurses and presumed knowledge and skill

Liu et al. To gain an insight into Phenomenological approach, semi- 20 cancer patients (10 Components of caring

(2006) the understanding of structured interview focused on men : 10 women, aged 1. Caring attitude of the nurse and caring in nursing from questions: "What must nurses say on average 51 years) their professional responsibility for the point of view of or do in order to make you feel that living in China. cancer patients and to they are taking care of you?" identify the concept of "What, in your experience, is caring in a Chinese caring behavior in nurses?" "What cultural context. should nurses improve in their work (in their relationship with patients)?" providing emotional support. 2. Professional skills and their professional responsibility for providing information, serving as support.

3. Professional skills and professional responsibility of nurses for providing of practical support

Poole and To describe nursing Semi-structured interview focusing Five clients in home For nurses, the following things are

Rowat behavior of nurses as on questions: "What does the client care (three women and important in care:

(1994) perceived by elderly of home care perceive as caring one married couple) 1. Personality of the nurse. clients in home care. $\quad$ behavior in nurses?" average age of 2. Emotional support of patients. respondents 78years. In 3. Physical support of patients. Canada.

Wilkin and To establish the Phenomenological approach 12 registered nurses Concept caring consists of Slevin importance of care for according to Heideggerian. Semi- working full time and 1. Feelings of nurses.

(2004) nurses in intensive care structured interview with open shift operation in Great 2. Knowledge of nurses. units. To establish questions type: "What does the Britain. whether the nature of concept of caring in connection 3. Skills of nurses.Also influenced care has an impact on with your work in the coronary nursing practice. $\quad$ care unit mean to you?"

Yam and To determine perception Interview with questions type: Students of Nursing behavior is:

Rossiter of nursing behavior in "Can you describe what you postgraduate studies 1 . As perfect as possible, meeting the (2009) nurses in Hong Kong, perceive as nursing behavior in with minimum two- needs of the client. obstacles affecting this clinical practice?" "What could years' practice, age of 2. Effective communication and behavior and possible prevent you from displaying this respondents was interpersonal skills. ways to overcome them. nursing behavior?" "How could between 26-37 years 3. Provision of favourable your nursing behavior be (with average 27.4), environment. invigorated in practice?" length of practice from 4-14 years. Hongkong. 
Nurses believe that caring can be learned through observation, practical experience, and self-reflection (Cheung, 1998).

\section{Caring as intervention of the nurse}

Nurses understand caring in this descriptive category as patient and attentive surveillance and actions which lead to the relief or alleviation of symptoms and improved comfort. They try to understand the symptoms of patients' illnesses and the language of their bodies through observation and assessment of vital functions, integrating important objective and subjective symptoms with other data. Nurses deal with difficult situations and decide whether to act or to wait and monitor the patient carefully. Caring is, thus, also the collection of data about patients which create the basis for nursing diagnostics, ratings and intervention to meet the individual bio-psychosocial and spiritual needs of patients: identification, risk assessment, and prevention of falls, ulceration, and malnutrition (Yam, Rossiter, 2009; Wilkin and Slevin, 2004; Andersson et al., 2015). Nurses working in coronary intensive care units emphasize, as a key theme, nursing knowledge and skills, professional competencies, and experience, which help nurses gain confidence (Wilkin, Slevin, 2004).

\section{Caring as a contextual link to multiple aspects}

According to nurses, caring is often influenced by the context in which it takes place. It is in short supply when there is a full load of work and at the same time insufficient staff, and time available for direct care of each patient is limited. In such situations priority is given to quantifiable results, treatment and essential care of patients (Wilkin, Slevin, 2004; Andersson et al., 2015). Nurses working in the intensive care unit state crisis management as an important aspect. They consider it very important that patients and their relatives remain calm during the process of hospitalization and even when dying (Wilkin, Slevin, 2004). According to Gustafsson et al. (2009), nurses attending to large numbers of elderly patients in different types of institutions at night take charge thanks to their sense of responsibility and the priority they give to caring, but also due to the responsibility they feel on behalf of other less qualified members of the nursing team. Meanwhile, they also provide support and supervision for the relatives of patients. In such circumstances, nurses have no time for direct contact with patients or their time together is extremely limited. Out of all the caring team, nurses take on the role of negotiator and advisor who must solve a number of different problems while providing care. They must also have great experience, knowledge and an overview of new trends, for example, in medical procedures. Yam and Rossiter
(2009) mention the supporting role of an environment in which colleagues cooperate, have the same aim, and support each other so that patients receive the best possible care. Although caring is considered to be the very essence of nursing, nurses state that if they do not receive adequate support in caring for patients or if they are hampered in doing so, they become disillusioned and demotivated. They also complain that their hands are tied by the hospital system and administration (Cheung, 1998).

Caring as a way of existence and way of understanding the nature of nursing

Some nurses regard caring as a philosophy, a way of life which gives life meaning. It is a meaningful activity and its results encourage nurses to persist with it (Cheung, 1998).

\section{Caring in nursing from the point of view of patients}

Analysis of the concept of caring from the perspective of patients is based on two articles which met the aforementioned criteria. Liu et al. carried out research on patients with oncological diseases (2006) and Poole and Rowat (1994) on home-care clients/patients.

According to Poole and Rowat (1994), patients who receive care in their own household perceive caring to have three attributes: emotional support, physical support and the personality of the nurse. Authors Liu et al. (2006) arrived at a similar conclusion.

\section{Emotional support in caring}

The research of Liu et al. (2006) on cancer patients in China suggests that patients feel the need for emotional support from nurses as they live under the constant stress of their life-threatening illnesses. Patients appreciate it when they are listened to carefully, when they can speak about their problems and feelings, and when they are given hope during illness. Nurses have proved to be an effective source of support. While nurses monitor and evaluate the patient continuously, patients do the same - watching and evaluating nurses. Their behavior and attitude leave an impression on patients according to which they assess whether or not nurses demonstrate a caring stance. The attitude of the nurse directly affects patient mood. According to accounts of cancer patients, basic caring behavior has several important components: a positive greeting from the nurse, friendly behavior, a pleasant tone of voice, a smile. Patients are sensitive to non-verbal communication. Nurses who work with active interest are judged as caring and patients appreciate how nurses reduce their depression and stress. At the same time, nurses facilitate mutual communication (Liu et al., 2006). 


\section{Physical support in caring}

According to Poole and Rowat (1994), patients are also sensitive to bodily care, for example, the measuring of blood pressure, monitoring of treatment, prescription of effective analgesia, transmission of information, and coordination of care. Patients value the experience and technical skill of nurses which make the performance of certain procedures painless. They appreciate it when the nurse is willing and able to eliminate physical discomfort, whether through direct help, good advice, or practical instruction (Liu et al., 2006). Patients' perception of caring is influenced by three factors: the professional knowledge of nurses, their attitudes, and skills. Patients evaluate the level of caring of nurses indirectly through these factors. The way patients perceive caring contributes to the creation of a relationship of trust, making it possible for them to find effective help and support (Liu et al., 2006).

\section{Personality of the nurse}

Above all, clients of home-care appreciate the good mood of nurses. By good mood they refer to a cheerful attitude, readiness to help, and the fact that the visit is conducted in a positive atmosphere. In addition, clients greatly appreciate it if nurses are able to understand their situation. They value their authenticity, sincerity, patience and respect for their person. There are two key variables in the relationship between home-care patients and nurses: reciprocity and contact. Reciprocity is understood as the need for the patient to give the nurse something back in return for her care, for example, small presents or sweets. The availability and reliability of nurses are of prime importance, regarding contact (Poole, Rowat, 1994). Patients also state that it is important for nurses to pay attention to every patient, since all require their psychological support. They appreciate non-directive communication and expect nurses to have time for them. They expect to be entitled to speak with them, not only about their illnesses, but also about everyday matters. Patients with cancer need information concerning treatment and care, and assert that the main source of information for them is nurses. In this way nurses help them adapt to their illness, and reduce the sense of helplessness (Liu et al., 2006).

Similarities and differences in perception of caring form the point of view of nurses and from the point of view of patients

Nurses and patients concur that to provide quality care it is necessary to create an individual relationship between both parties, based on trust. Communication in such a relationship is automatic. Nurses realize, and patients confirm, that listening to patients and providing them with important information are essential, leading to a reduction in anxiety and stress (Wilkin, Slevin, 2004; Liu et al, 2006; Gustafsson et al., 2009; Yam, Rossiter, 2009; Andersson et al., 2015).

Both groups realize the importance of support from nurses. Nurses blend empathy and caring with this support, protecting patients and their personal interests (Cheung, 1998; Wilkin, Slevin, 2004; Liu et al., 2006; Andersson et al., 2015).

Patients and nurses state that the availability of nurses whenever needed is an important aspect of caring. Their availability and physical presence brings comfort (Poole, Rowat, 1994; Cheung, 1998; Wilkin, Slevin, 2004; Andersson et al., 2015).

Both groups affirm the importance of physical care for the patient. They agree on the importance of the issues of pain, the monitoring of symptoms, the monitoring of physiological functions, and how care is coordinated. Patients appreciate the experience and technical skills of nurses, which make it possible to experience painless medical procedures. They also appreciate it when the nurse is able to help them willingly with the removal of physical discomfort either by direct help or through good advice or practical instruction. Nurses confirm the importance of experience, knowledge, skills and professional competencies in caring for patients (Poole, Rowat, 1994; Wilkin, Slevin, 2004; Liu et al., 2006; Yam, Rossiter, 2009; Andersson et al., 2015).

Patients also notice and evaluate the way in which information is delivered during care. Nurses feel that transmission of information is crucial, and nursing documentation is an important source of information (Poole, Rowat, 1994; Wilkin, Slevin, 2004).

Patients describe how the attitude of nurses towards them has an immeasurable affect on their state of mind (Liu et al., 2006), which is not necessarily clear from the comments of nurses.

Patients with oncological diseases consider verbal elements of communication, such as an active greeting, to be important aspects of the attitude of nurses, along with non-verbal communication, for example, a friendly demeanour, accompanied by a smile and a pleasant tone of voice (Liu et al., 2006).

Nurses state that for provision of quality care it is necessary to demonstrate their kindness and attentiveness to the patient, to listen to them and to help. Experience, and their own personal strength of character and courage are necessary for this (Wilkin, Slevin, 2004; Yam, Rossiter, 2009; Andersson et al., 2015). Unlike patients, they focus on factors that can complicate the provision of caring, crucial among which are insufficient staffing and a heavy workload 
(which result in a reduction in contact time with patients), and the hospital organizational system and administration. Meanwhile, they remark that if they do not have sufficient support, they feel disillusioned and demotivated (Cheung, 1998; Wilkin, Slevin, 2004; Andersson et al., 2015). In addition, nurses are aware of their responsibility not only for the client, but also for the less qualified members of the nursing team, and for providing support and supervision in caring for patients' relatives (Yam, Rossiter 2009).

Some nurses perceive caring as an essential part of human life (Cheung, 1998); however, this opinion is not voiced by patients in the cited articles.

\section{Discussion}

The inclusion of caring as a central concept in the discipline of nursing has been the subject of stormy debates. Despite opposition, theoretical, research and practical models concerning caring in nursing have been developed over the last forty years. More than sixty books and thousands of professional articles have been written about the concept of caring in the discipline of nursing. At the insistence of Madeleine Leininger, the National Caring Research Conference (USA, 1978) was set up with the aim of making it possible for professionals engaged in the theory and research of caring in nursing to meet (Smith 2013).

The concept of caring in nursing is defined variously in the literature. Hegedus (1999) states that caring is central, the main essence of nursing practice, and is expressed in the actions and behavior of nurses. According to Kyle (1995), caring is the main concept in the nursing profession. Benner and Wrubel (1989) describe caring as the centrepiece and primary essence of medical practice. Caring is the moral and ethical starting-point of nursing and its foundations. (Condon, 1988; Fry 1988). Finfgeld-Connett (2008) characterize caring as the essence of the concept of nursing. It is an interpersonal process, based on professional growth, professional skills and sensitivity, and it is one of ethical foundations of nursing. According to Watson $(1985 ; 2002)$, caring has a central and demonstrable place in nursing, as it provides a valuable basis for the profession, as well as a field for further research and knowledge. Gastmans (1999) suggests that caring is characterized by its moral side, expressed by the internal attitude and external actions of nurses. These two aspects are included in the concept of caring behavior, which is the moral component of nursing.

Nursing behavior is defined as an interactive and intersubjective process which occurs between nurses and patients in a moment of shared vulnerability. This moment is controlled fully by both participants and it starts as soon as nurses respond to a patient and do everything for their good (Gaut, 1983; Watson, 1985; Wolf, 1986).

Five basic views of the nature of caring were defined through content analysis of research works, and they define it as a human trait, the natural condition of a human being, as a moral imperative, ideal, virtue, value, as affection for oneself, for patients, and the work, as interpersonal interaction, as something existing between two persons, and, finally, as therapeutic intervention, an intentional act with a planned aim (Smith et al., 2013).

\section{Conclusion}

Caring in nursing is perceived variously and it is not easy to define this phenomenon, despite the fact that the opinions of nurses and patients coincide in certain areas. The process of caring is described as a content specific interpersonal process which is characterized by the professional knowledge of nurses, their skills, personal maturity and interpersonal sensitivity, resulting in the protection, emotional support, and meeting of the bio-psycho-social needs of patients. For the purpose of professionalism, caring must be open to clients and based on moral foundations. It is also important to create a favourable environment in which the process can take place. Nurses perceive caring in nursing as a relationship between nurses and patients which is characterized on their part by individual attitude, attentiveness, experience and sensitivity. Within this relationship, communication takes place with elements of active listening, and expressions of understanding and empathy. Information is provided which reduces anxiety and leads to the overcoming of obstacles. This relationship helps to protect clients' safety, autonomy, dignity and comfort. However, it requires nurses to have experience, and it is influenced by the environment, for example, personal security, workload, available time, and the health of clients. Caring is a way of understanding the nature of nursing. Nurses' personalities, their availability and reliability, and emotional and physical support are important in the caring of patients. Caring is still developing, and it is a challenge both for theorists and for nurses in practice (Andersson et al., 2015). It is a meaningful activity and its results encourage nurses to persist with it. Caring stands above nursing, providing it with direction, orientation, substance and value (Cheung, 1998).

\section{Benefits for practice and further research}

The findings reported could help to elucidate the nature of caring as an essential component of nursing, and to understand and preserve its values. 
Furthermore, it could be used in comparison with other similarly oriented studies.These results could also be used in the field of nursing education, i.e., for teaching in subjects concerned with nursing care and communication between nurses and patients, and for the development of patient-centred care.

\section{Limitation of the study}

Only publications in English language, available in electronic bibliographic databases were incorporated into our study.

\section{Ethical aspects and conflict of interest}

We declare that the research survey, conducted in the form of an overview study, has no conflicts of interest and complies with ethical standards.

\section{Author contributions}

Conception and design (LD, DJ), data analysis and interpretation (LD), manuscript draft (LD), critical revision of the manuscript (DJ), final approval of the manuscript (LD, DJ).

\section{References}

Andersson EK, Willman A, Sjöström-Strand A, Borglin G. Registered nurses' descriptions of caring: a phenomenographic interview study. BMC Nursing. 2015;14:16

Benner P, Wrubel J. The primacy of caring: Stress and coping in health and illness. 1st ed. Menlo Park California: Addison - Wesley Publisher Co, 1989.

Condon EH. Reflections on caring and the moral culture of nursing. Virginia Nurse. 1988;56(4):23-27.

Filipec J. et al. Slovník spisovné češtiny pro školu a veřejnost: $s$ dodatkem MŠMT. 4. vyd. Praha: Academia; 2005. (in Czech)

Finfgeld-Connett D. Qualitative convergence of three nursing concepts: art of nursing, presence and caring. Journal of Advanced Nursing. 2008;63(5):527-534.

Fry ST. The ethic of caring: can it survive in nursing? Nursing Outlook. 1988;36(1):48.
Gastmans C. Care as a moral attitude in nursing. Nursing Ethics. 1999;6(3):214-223.

Gaut DA. Development of a theoretically adequate description of caring. Westernal Journal of Nursing Research. 1983;5(4):313-324.

Gustafsson C, Asp M, Fagerberg I. Municipal night nurses' experience of the meaning of caring. Nursing Ethics. 2009;16(5):599-612.

Hegedus KS. Providers' and consumers' perspective of nurses' caring behaviours. Journal of Advanced Nursing. 1999;30(5):1090-1096.

Cheung J. Caring as the ontological and epistemological foundations of nursing: a view of caring from the perspectives of Australian nurses. International Journal of Nursing Practice. 1998;4(4):225-233.

Kutnohorská J. Etika v ošetrovatelství. 1. vyd. Praha: Grada; 2007. (in Czech)

Kyle TV. The concept of caring: a review of the literature. Journal of Advanced Nursing. 1995;21(3):506-514.

Leininger MM. Transcultural care diversity and universality: a theory of nursing. Nursing Health Care. 1985;6(4):208212.

Liu JE, Mok E, Wong T. Caring in nursing: investigating the meaning of caring from the perspective of cancer patients in Beijing, China. Journal of Clinical Nursing. 2006;15(2):188196.

Poole G, Rowat K. Elderly clients' perceptions of caring of a home-care nurse. Journal of Advanced Nursing. 1994;20(3):422-429.

Smith MC, Turkel MC, Wolf ZR. Caring in nursing classics: an essentials resource. New York: Springer Publishing Company, LLC; 2013.

Watson J. Nursing: The philosophy and science of caring. Boston: Little, Brown and Company. Boulder, CO: University Press of Colorado; 1985.

Watson J. Assessing and measuring caring in nursing and health sciences. New York: Springer Publishing Company, LLC; 2002.

Wilkin K, Slevin E. The meaning of caring to nurses: an investigation into the nature of caring work in an intensive care unit. Journal of Clinical Nursing. 2004;13(1):50-59.

Wolf ZR. The caring concept a nurse identified caring behaviors. Topics in Clinical Nursing. 1986;8(2):84-93.

Yam BM, Rossiter JC. Caring in nursing: perceptions of Hong Kong nurses. Journal of Clinical Nursing. 2009;9(2):293-302. 